\title{
A Review of the Fatigue Behaviour of Components Coated with Thin Hard Corrosion-Resistant Coatings
}

\author{
Sergio Baragetti ${ }^{*}, 1,2$ and Federico Tordini ${ }^{2}$

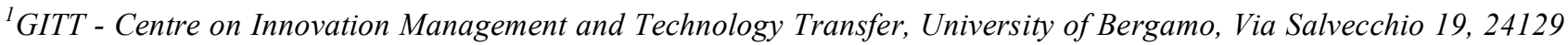 \\ Bergamo, Italy \\ ${ }^{2}$ Department of Design and Technology, University of Bergamo, Viale Marconi 5, 24044 Dalmine, Italy
}

\begin{abstract}
This paper provides a review of the state of the art on the study of the fatigue behaviour of mechanical components coated with thin hard corrosion-resistant coatings such as the physically or chemically vapour deposited ones. Some references address the experimental characterization of the fatigue resistance of coated steel and light alloys. Some coatings have been observed to prove effective against fatigue both in air and in aggressive environment. Numerical models and theoretical-numerical procedures have also been developed to shed light on the fatigue behaviour of coated components and to foresee the number of cycles until failure. As a matter of fact, the combination of good fatigue and anti-corrosion properties can significantly increase the performances of mechanical components operating in aggressive environments.
\end{abstract}

Keywords: Fatigue, corrosion-fatigue, thin hard coatings, residual stresses, theoretical-numerical models.

\section{INTRODUCTION}

Physically and chemically vapour deposited (PVD and CVD) thin hard coatings were first introduced a few decades ago in the field of the machining tools and dies. Many other industries such as the aerospace and the automotive ones $[1,2]$ have had a huge interest in them from then on. The good tribological and anti-corrosion performances achievable with these deposits have been highlighted by several research studies [3-10]. Furthermore, these coatings can have an influence on the fatigue and the corrosionfatigue behaviour of mechanical components [11-24]. The residual stresses introduced by the deposition process are supposed to be mainly responsible for this. In particular, surface compressive stresses can prove effective against fatigue either by preventing crack nucleation or by retarding the propagation and fatigue cracks are expected to initiate where the maximum tensile stresses occur. Remarkable improvements in the fatigue resistance can also be given by electroless ion plating [25]. Some references dealing with thin hard-coated component modelling are also available $[15,16,24,26-30]$. However, most of them are focused on coating characterization rather than on the simulation of fatigue crack formation and propagation. Theoreticalnumerical procedures to foresee the fatigue life of coated components were developed and showed good accordance with the experimental evidence $[15,16]$. Nevertheless, further numerical and experimental studies would be important to shed light on the effects of thin hard coatings on the fatigue and the corrosion-fatigue resistance of coated components. Particularly, the effects produced by varying the deposition

*Address correspondence to this author at the Department of Design and Technology, University of Bergamo, Viale Marconi 5, 24044 Dalmine, Italy; Tel: 0039-0352052382; Fax: 0039-0352052310;

E-mail: sergio.baragetti@unibg.it process and coating parameters such as thickness and elastic modulus would deserve particular attention [24,31].

This work focuses on the main results available in the literature on the fatigue and the corrosion-fatigue behaviour of thin hard-coated steel and light alloys. As a matter of fact, despite the progress made by the current deposition technique, more and more effective coatings are expected to be produced to fulfill the requirements of each single base material and application in the best possible way. Also, the opportunity to lighten mechanical components is becoming a crucial need, especially in those applications for which the request for more power with lower $\mathrm{CO}_{2}$ emission is expected to become more and more important. From this point of view, the use of suitably coated light alloys having similar or even better performances than those of traditional construction steels would be advisable for a number of applications. Based on these issues, a larger and larger number of research studies would be necessary to achieve significant results, as few papers involved in this area can be found in the literature for the time being.

\section{EXPERIMENTAL RESULTS}

A thorough collection of recent experimental results from fatigue tests on thin-hard coated metallic samples is outlined in this section. These works have been focused on both steel and light alloys. The main results are summarized in Table 1 except when a broad range of different alternating stresses was investigated.

\subsection{Fatigue Behaviour of Thin Hard-Coated Steel Alloys}

The fatigue behaviour of coated tool and stainless steels has been particularly studied because the anti-corrosion and wear properties of the deposits suit the requirements of the applications which these base materials are largely used for. 
Table 1. Some Results from Fatigue Tests on Different Coatings and Base Materials

\begin{tabular}{|c|c|c|c|c|c|c|c|}
\hline \multirow{2}{*}{\multicolumn{2}{|c|}{ Base material }} & \multirow{2}{*}{ Test Condition } & \multirow{2}{*}{ Coating } & \multicolumn{2}{|c|}{ Fatigue Limit, MPa } & \multirow{2}{*}{$\Delta \%$} & \multirow{2}{*}{ Refs. } \\
\hline & & & & Coated & Uncoated & & \\
\hline \multirow{9}{*}{ 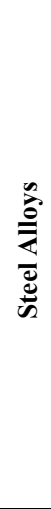 } & EDM AISI D2 & $\begin{array}{l}\text { Bending fatigue, various nos. of cycles and } \\
\text { machining conditions }\end{array}$ & TiN & - & - & $+10.9 \div 29.4$ & {$[11]$} \\
\hline & $316 \mathrm{~L}$ & Rotating bending, $5 \times 10^{6}$ cycles & TiN & $381 \pm 2$ & $464 \pm 2$ & +22 & {$[12]$} \\
\hline & \multirow{2}{*}{$316 \mathrm{~L}$} & Rotating bending, $5 \times 10^{6}$ cycles, air & \multirow{2}{*}{ DLC } & 496 & 460 & +7 & \multirow{2}{*}[13]{} \\
\hline & & Rotating bending, $5 \times 10^{6}$ cycles, $\mathrm{NaCl}$ sol. & & 493 & 386 & +27 & \\
\hline & \multirow{2}{*}{ AISI 302} & \multirow{2}{*}{ Rotating bending, $3 \times 10^{5}$ cycles } & $\mathrm{CrN}$ & $852 \pm 20$ & \multirow{2}{*}{$721 \pm 17$} & +18 & \multirow{2}{*}{ [14] } \\
\hline & & & $\mathrm{CrN}+\mathrm{DCT}$ & $860 \pm 31$ & & +19 & \\
\hline & 2205 & Four-point bending, $2 \times 10^{6}$ cycles & $\mathrm{CrN}$ & $585 \pm 26$ & $510 \pm 18$ & +15 & {$[15,16]$} \\
\hline & H11 & Four-point bending, $2 \times 10^{6}$ cycles & $\mathrm{CrN}$ & $845 \pm 43$ & $730 \pm 26$ & +16 & {$[16]$} \\
\hline & 39NiCrMo3 & Rotating bending, $10^{7}$ cycles & $\mathrm{SiO}_{x}$ & $503 \pm 23$ & $538 \pm 21$ & -10 & {$[17]$} \\
\hline \multirow{6}{*}{ 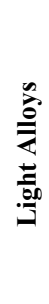 } & $6082-\mathrm{T} 6$ & Rotating bending, $10^{7}$ cycles & $\mathrm{CrN}$ & $142 \pm 10$ & $165 \pm 11$ & -14 & [16] \\
\hline & \multirow{3}{*}{ 2011-T6 } & \multirow{3}{*}{ Rotating bending, $10^{7}$ cycles } & $\mathrm{WC} / \mathrm{C}$ & $169 \pm 15$ & \multirow{3}{*}{$154 \pm 6$} & +10 & \multirow{3}{*}{ [21] } \\
\hline & & & DLC & $162 \pm 6$ & & +5 & \\
\hline & & & $\mathrm{SiO}_{x}$ & $162 \pm 7$ & & +5 & \\
\hline & \multirow{2}{*}{ Ti-6Al-4V } & Rotating bending, $2 \times 10^{5}$ cycles, smooth & $\mathrm{TiN}$ & $574 \pm 45$ & $646 \pm 45$ & -12 & \multirow{2}{*}[24]{} \\
\hline & & Rotating bending, $2 \times 10^{5}$ cycles, notched & TiN & $281 \pm 9$ & $327 \pm 14$ & -14 & \\
\hline
\end{tabular}

Some studies on other structural steel alloys can also be found.

In [11], Guu and Hocheng studied the fatigue behaviour of TiN-coated EDM AISI D2 tool steel samples. Excellent coating adhesion and high surface hardness coupled with a slightly decreased surface roughness were pointed out for the coated material. Remarkable improvements in the bending fatigue life from 10.9 to $29.4 \%$ depending on the machining parameters were found (Table 1). The residual compressive stresses induced by the deposition process were supposed to have compensated for the detrimental tensile stresses left by the EDM process on the machined surfaces.

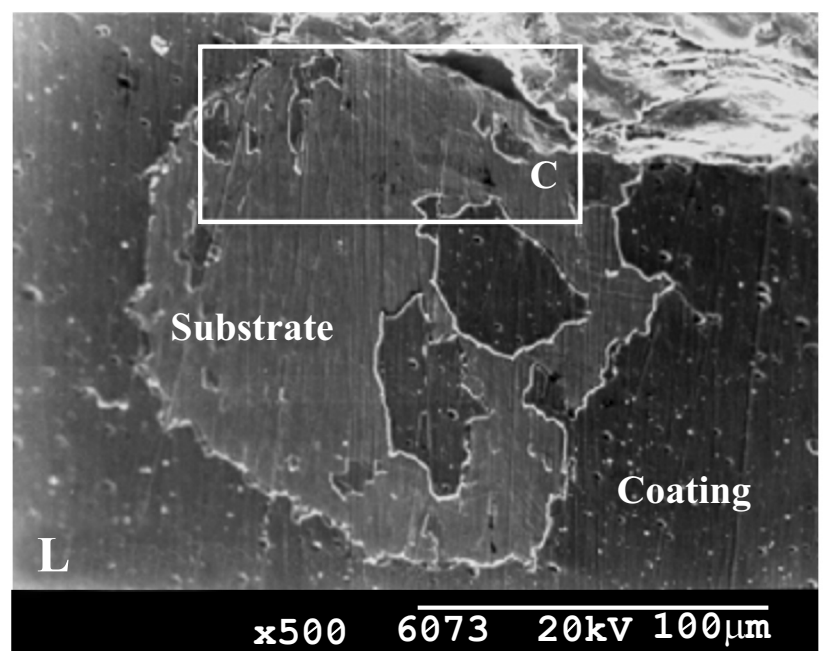

(a)
Puchi-Cabrera et al. investigated the rotating bending fatigue behaviour of $316 \mathrm{~L}$ stainless steel coated with different thin films [12,13]. In [12], TiN was deposited on $316 \mathrm{~L}$ samples to evaluate their fatigue behaviour in comparison with that of uncoated samples. The fatigue limit of the coated material at $5 \times 10^{6}$ load cycles was increased by $22 \%$ (Table 1). Microscope observations of the fracture surfaces highlighted that $\mathrm{TiN}$ had delaminated at high alternating stresses (Fig. 1). Compressive residual stresses of about 7.08 GPa were XRD-detected in the coating and were believed to have been the main reason behind the improved fatigue behaviour of the coated samples. Fatigue cracks nucleated at the sample surface and propagated either

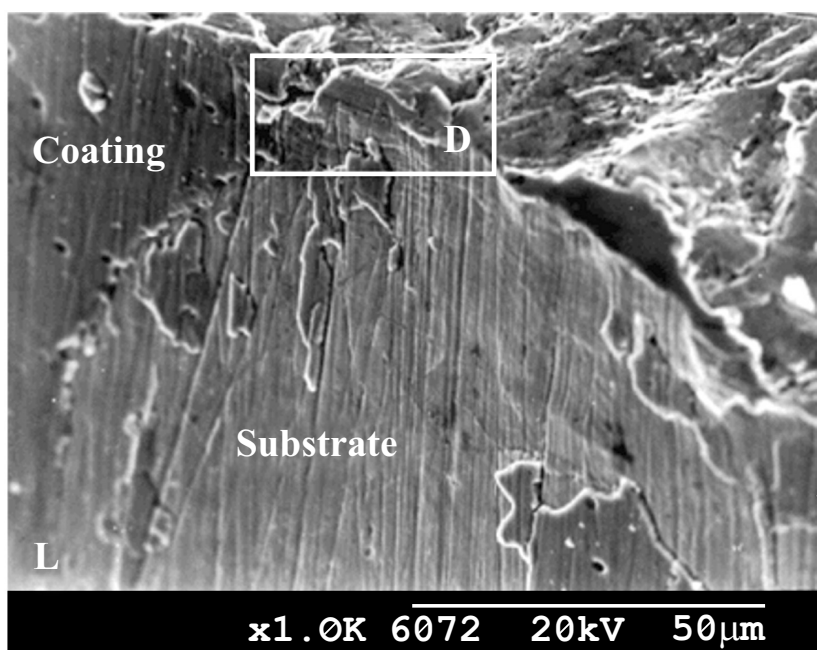

(b)

Fig. (1). (a) Lateral wall of a TiN-coated 316L sample failed at an alternating stress of $510 \mathrm{MPa}$. The coating delamination could have been promoted from the crack initiation site. (b) Magnification of the area depicted as C in Fig. (1a) [12]. 


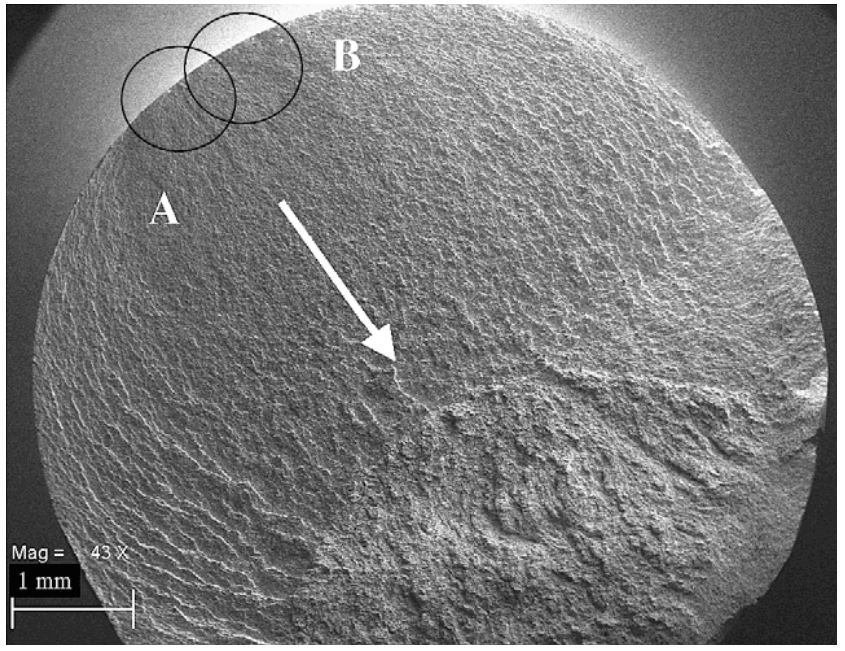

(a)

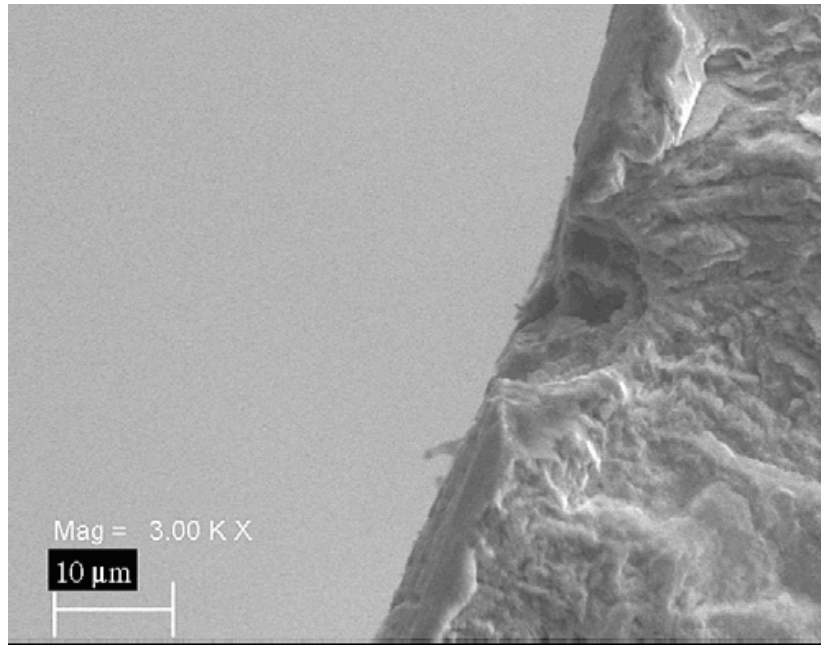

(b)

Fig. (2). (a) Fracture surface overview of a $\mathrm{SiO}_{x}$-coated $39 \mathrm{NiCrMo} 3$ sample and (b) higher magnification of the crack initiation site depicted as B in Fig. (2a) [17].

towards the samples core or along the coating-substrate interface. It was concluded that the deposition of TiN to enhance the anti-corrosion, -galling and -wear properties of $316 \mathrm{~L}$ was also effective in improving the fatigue properties. Supported by these results, in [13] the fatigue behaviour of 316L coated with a different and very hard DLC (Diamond Like Carbon) film deposited by PVD magnetron sputter ion plating was studied. In this case the tests were carried out both in air and in $3 \mathrm{wt} \% \mathrm{NaCl}$ solution. The coating was beneficial to the fatigue behaviour of the base material, particularly under corrosive conditions. The fatigue limit at $5 \times 10^{6}$ load cycles in the presence of the coating was increased by more than $7 \%$ and $27 \%$ in air and in $\mathrm{NaCl}$ solution respectively (Table 1). The improved corrosionfatigue behaviour was believed to have been strongly related to the amorphous nature of the hydrogenated carbon layer deposited onto the crystalline $\mathrm{Cr}-\mathrm{C}$ layer in contact with the steel substrate. Furthermore, the high mechanical strength of the coating, the possible residual compressive stresses in the surface layers of the coated samples and the good coating adhesion were all supposed to have contributed to the overall increase in the fatigue performances of the coated samples. The remarkable results achieved in corrosive medium must be underlined and new experiments on different base materials coated with DLC should be addressed to check the potentials of this coating from this point of view.

In [14], the influence of deep cryogenic treatment (DCT) and PVD CrN coating on the fatigue behaviour of AISI 302 stainless steel was studied by considering the effects of the single treatments and of their combination. The $\mathrm{CrN}$ coating improved the fatigue resistance of the base material significantly (Table 1). Possible surface residual compressive stresses introduced by the PVD deposition process were supposed to have mainly contributed to this improvement. By contrast, the additional DC treatment after coating deposition did not produce any significant further improvement confirming the higher effectiveness of the PVD process.

Both stainless and tool steels were studied by Baragetti et al. in $[15,16]$. Four-point bending tests were carried out on uncoated and PVD CrN-coated 2205 stainless steel and H11 tool steel samples (Table 1). X-ray measurements were performed to detect the surface residual compressive stresses which fell in the range -1.5 to $-1.7 \mathrm{GPa}$ in the coated 2205 samples and were higher than $-2.4 \mathrm{GPa}$ in the coated $\mathrm{H} 11$ ones. As highlighted by the numerical data reported in Table 1, remarkable outcomes were observed for both the H11 and the 2205 samples with fatigue strength increases between $15 \%$ and $16 \%$.

Studies on coated high strength structural steel alloys were also addressed by researchers. In [17], $\mathrm{SiO}_{x}$ was deposited on quenched and tempered $39 \mathrm{NiCrMo} 3$ steel samples by plasma enhanced-CVD (PE-CVD). The samples were tested under rotating bending in laboratory air at room temperature. Negligible residual stresses were believed to have been generated by the low deposition temperature of the PE-CVD process. Accordingly, fatigue cracks nucleated on the external surface (Fig. 2). As reported in Table 1, the coating was somewhat detrimental to the fatigue resistance of the base material. Scratch tests showed some coating elasticity and acceptable coating-substrate adhesion. Based on the relatively limited worsening of the fatigue resistance, the deposition of $\mathrm{SiO}_{x}$ on steel could prove effective for applications requiring high resistance to scratch and corrosion and involving relevant fatigue loads.

Another structural steel alloy, say quenched and tempered 4140, coated with thin hard low friction Cr coating was studied in [18]. Rotating bending tests carried out at different alternating stresses showed that both the fatigue life and limit of the coated samples were significantly reduced in comparison with those of the uncoated ones, i.e. by up to $88 \%$ and $21 \%$ respectively. Despite SEM observations showed that the coating remained well adherent to the substrate during the fatigue tests, multiple crack initiation sites at the substrate-deposit interface were observed (Fig. 3). This suggested that the coating had acted as a crack source for the steel substrate making the use of $\mathrm{Cr}$ coated 4140 steel potentially critical for structural applications involving high numbers of load cycles.

$\mathrm{Cr}-\mathrm{Mo}-\mathrm{V}$ steels used for high temperature steam turbine rotor components have been found to be base materials 
which can take advantage of coating deposition. The effects of wear-protective, heat- and corrosion-resistant thin hard ceramic coatings on the fatigue behaviour of steels were examined in $[19,20]$. In [19], Kim et al. characterized the mechanical properties of TiN, TiCN and TiAlN deposited by arc ion plating on $\mathrm{Cr}-\mathrm{Mo}-\mathrm{V}$ steel and carried out both rotating bending tests and axial constant amplitude loading tests on CT samples up to high cycle fatigue lives. Good adhesion to the substrate was found and high compressive residual stresses from crystal growth were produced in the coating layers. The fatigue strengths of the coated samples were higher, especially at long fatigue lives, for all the coating thicknesses investigated. It was believed that the fatigue strength improvement of the coated material was mainly due to the constraint of plastic deformation of the substrate by hard coating layer and high compressive residual stresses. Furthermore, the fatigue crack growth rates observed were not altered over the full range of $\Delta K$ by the coating presence regardless of the thickness. The high temperature effect was accounted for in [20] by Suh et al. who investigated the rotating bending fatigue resistance of $1 \mathrm{Cr}-1 \mathrm{Mo}-0.25 \mathrm{~V}$ steel coated with PVD TiN and TiAlN coatings. Particularly, the tests on the TiAlN-coated samples were carried out at both room and high temperature. Good results were observed at room temperature because of the high surface residual compressive stresses, whereas the fatigue strength dramatically decreased at $400^{\circ} \mathrm{C}$ and $538^{\circ} \mathrm{C}$. Such behaviour was associated with the residual stress relief in the coating resulting from the temperature increase. This clearly represents a serious problem to face with further research studies to allow larger and larger use of these coatings in high temperature applications.

The following points are remarked from the review of the experimental studies on thin hard-coated steel alloys reported in this section:

- $\quad$ The fatigue behaviour of steel alloys coated with thin hard wear- and corrosion-resistant coatings has not been studied enough yet. In fact, despite encouraging and sometimes remarkable results have been collected both in

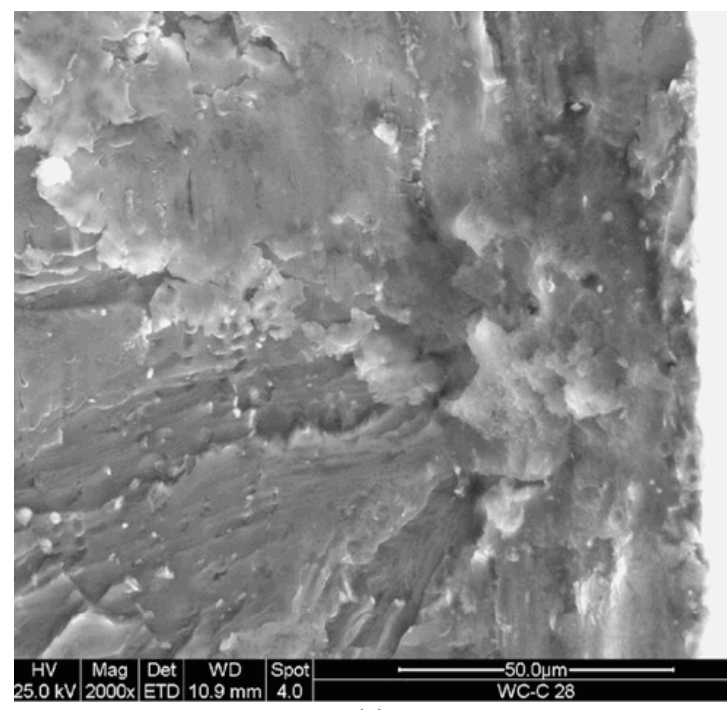

(a) air and in corrosive environment, there are few authors who have devoted their research interest on this subject.

- As a matter of fact, the range of base materials and coatings investigated up until now should be broadened to achieve the optimization of the performances of the coated components. The design of suitable experiments to define the most effective combinations of coating and base material as well as the best adjustment of the deposition process parameters to maximize the mechanical properties of the coated components could be fundamental from this point of view.

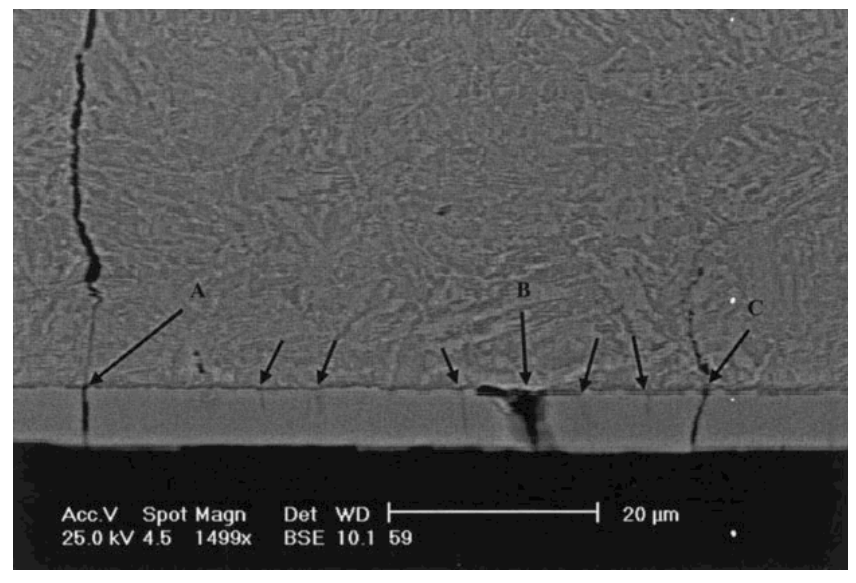

Fig. (3). Detail of the substrate-coating interface area of a sample tested at an alternating stress of $563 \mathrm{MPa}$ showing several coating fractures acting like crack initiation sites for the base material [18].

- $\quad$ Based on the results collected, TiN e $\mathrm{CrN}$ coatings have shown the best performances in terms of fatigue resistance. The residual compressive stresses generated by the coating deposition process were believed to have been the main reason for the improvements achieved. These coatings have been applied successfully to both tool and stainless steels. However, the high deposition temperatures - which are largely responsible for the higher residual stresses induced - may prevent them

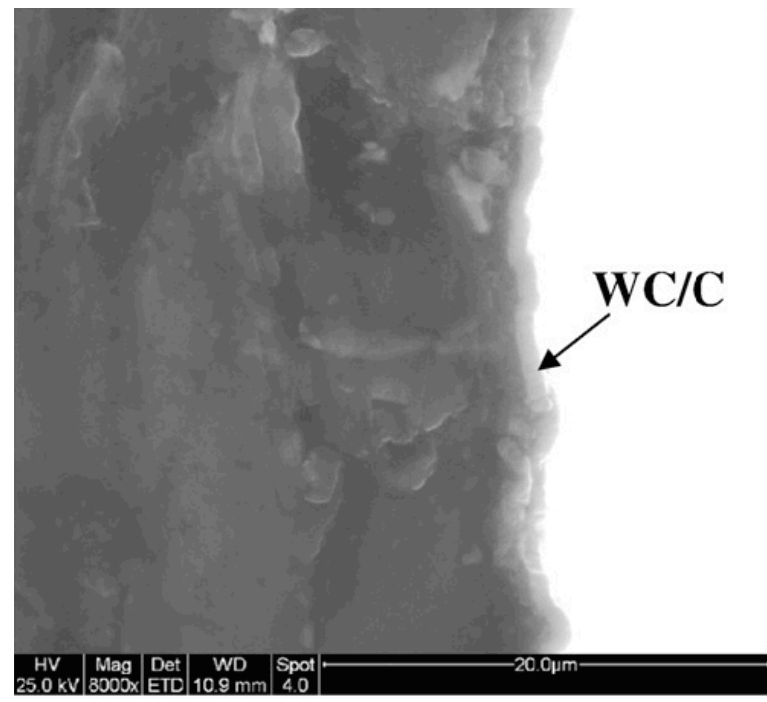

(b)

Fig. (4). (a) Magnification of the crack nucleation site of a 2011-T6 WC/C-coated sample tested at $190 \mathrm{MPa}$ and failed after 890,178 cycles showing the subsurface initiation and (b) higher magnification in the vicinity of the external surface [21]. 
from being studied more extensively and over a wider range of base materials.

- The current deposition technique is expected to obtain better improvements from coatings deposited at lower temperatures.

\subsection{Fatigue Behaviour of Thin Hard-Coated Light Alloys}

Notwithstanding aluminium and titanium alloys are the main light metal alloys for structural applications, their fatigue behaviour after coating deposition has not been studied as much as it has been done for steel alloys. In fact, only few references can be found in the literature.

In [16], rotating bending tests on PVD CrN-coated 6082T6 aluminium samples were carried without finding good results for the fatigue resistance of the base material (Table 1). The ineffectiveness of the coating was due to its impossibility to sustain the strains imposed on the overaged aluminium base material. This led to multiple cracking of the coating.

In [21], 2011-T6 aluminium alloy was PVD- and CVDcoated with $\mathrm{WC} / \mathrm{C}, \mathrm{DLC}$ and $\mathrm{SiO}_{x}$ films. Rotating bending tests on coated and uncoated samples were carried out in laboratory air at room temperature. The best results were found for the $\mathrm{WC} / \mathrm{C}$ coating - the average value of the limiting alternating stress of the coated samples at $10^{7}$ load cycles was increased by $10 \%$ (Table 1). The subsurface crack initiation observed on WC/C-coated 2011-T6 sample fracture surfaces (Fig. 4a) was associated with the presence of possible residual compressive stresses. The good adhesion shown by the coating (Fig. 4b) was also supposed to have contributed to the fatigue resistance improvement.

A significant reduction in both the static and the fatigue resistance of 7075-T6 aluminium alloy was observed by depositing a PVD ZrN coating [22]. Nevertheless, the least negative results were found under corrosive conditions and low alternating stresses: in $\mathrm{NaCl}$ solution at maximum alternating stresses below $220 \mathrm{MPa}$ the coated samples showed performances similar to those of the uncoated ones. In fact, the coating remained well adherent to the base material protecting it from the corrosive medium. By

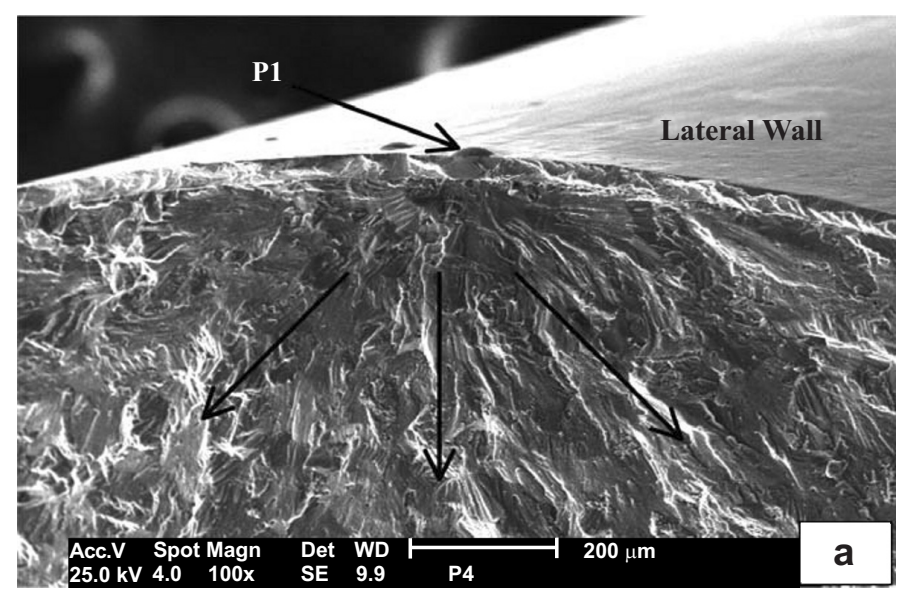

(a) contrast, in [25] good results for the fatigue and the corrosion-fatigue behaviour of 7075-T6 coated with an electroless Ni-P (EN) deposit were found. It was remarked that under corrosive condition, say in $3 \mathrm{wt} \% \mathrm{NaCl}$ solution, the amorphous structure of the coating was effective against pitting and multiple fatigue crack nucleation. Increments not lower than $55 \%$ in the fatigue life of the tested samples were produced. Nodular defects present on the surface of the coated samples were observed to be associated with fatigue crack nucleation sites, particularly at high alternating stresses (Fig. 5). The very good adhesion, the high mechanical strength and possible compressive stresses in the coating were supposed to have had a very high influence on the improvements achieved in the fatigue behaviour of the base material.

Studies on the fatigue behaviour of coated titanium alloys are almost absent in the literature. In [24], the fatigue behaviour of TiN PVD-coated Ti-6Al-4V smooth and notched samples was studied. The presence of the coating lowered the fatigue resistance of the base material and a similar decrease in the range $12-14 \%$ was found for the smooth and the notched samples (Table 1). This behaviour was investigated by numerical modelling as reported in the next section. As a matter of fact, more experimental studies are necessary to shed light on the fatigue behaviour of thin hard-coated titanium alloys.

Finally, Braun et al. [23] studied the oxidation and fatigue behaviour of $\gamma$-TiAl intermetallic alloy for high temperature applications coated with high power impulse magnetron sputtered (HIPIMS) $\mathrm{CrAlYN} / \mathrm{CrN}$ nanoscale multilayer coatings. The coatings were effective in protecting the substrate from oxidation at 850 and $900^{\circ} \mathrm{C}$. However, the fatigue strength $(\mathrm{R}=-1)$ of the coated alloy thermally exposed to air at $850^{\circ} \mathrm{C}$ for $300 \mathrm{~h}$ was significantly reduced in comparison with that of the as-received material from about $730 \mathrm{MPa}$ down to about $660 \mathrm{MPa}$.

Based on the reported results, it is important to stress that:

- The fatigue behaviour of thin hard-coated light alloys has been studied even less than that of coated steels. This allows for a plenty of research opportunities, being

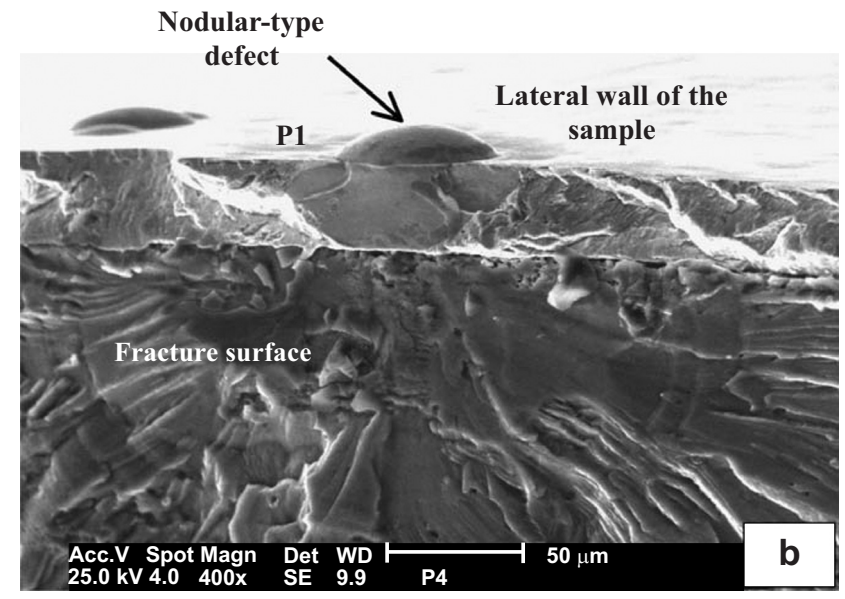

(b)

Fig. (5). Micrographs showing the association of the crack initiation site with a nodular surface defect in a 7075-T6 electroless Ni-P-coated sample failed at an alternating stress of $219 \mathrm{MPa}$ [25]. 


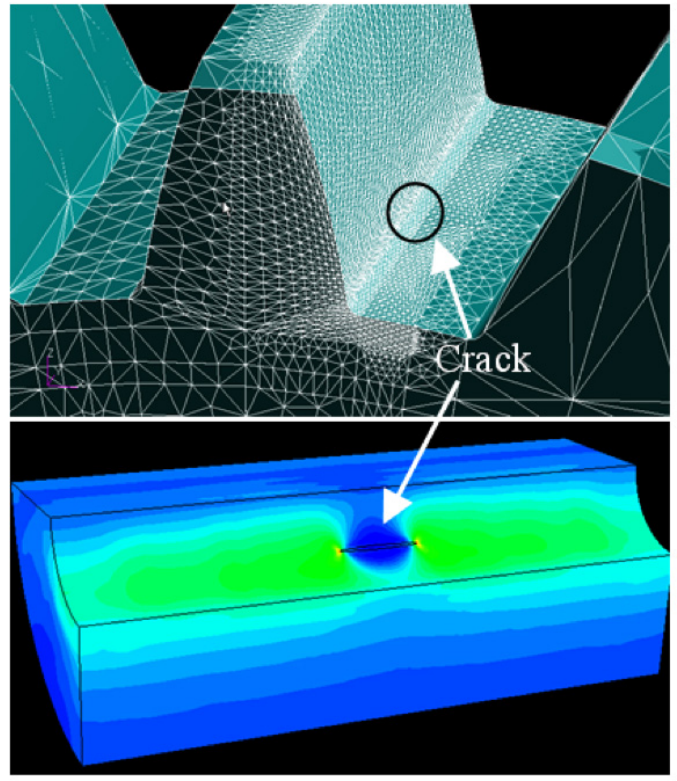

(a)
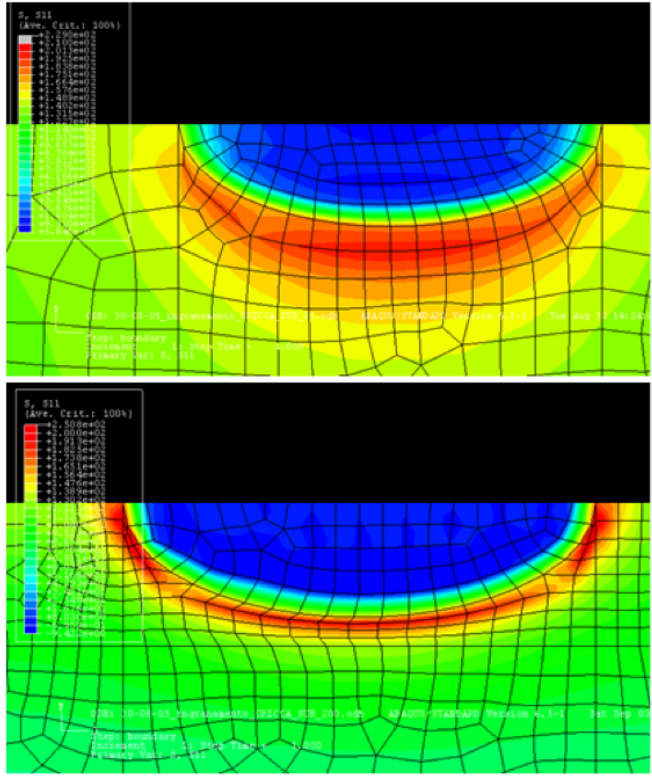

(b)

Fig. (6). (a) Mesh appearance at tooth root and stress state around the defect area and (b) stress contour map at the propagating fronts of the 5 and $200 \mu \mathrm{m}$-deep cracks in a PVD-coated steel gear studied in [26].

also considered that most of these materials are used for advanced structural applications.

- A few good results were found for aluminium alloys tested under rotating bending in both laboratory air and $\mathrm{NaCl}$ solution. As a matter of fact, the good corrosionfatigue properties guaranteed by some coatings should be investigated more extensively for a wide range of light base materials.

- The worst results were collected for aluminium and titanium alloys coated at high deposition temperatures, confirming that this is a key parameter to account for if one aims to improve the mechanical strength of this class of structural materials by depositing wear- and corrosion-resistant coatings.

\section{NUMERICAL MODELS}

The corrosion-fatigue behaviour of thin hard-coated components has not been numerically studied yet. Also, numerical models able to predict the fatigue life are almost missing in the literature.

In $[15,16,26]$, Baragetti et al. developed a theoreticalnumerical model to predict the fatigue life of thin hardcoated components. By simulating an initial defect in the FE model of a coated component and by introducing the residual stress field generated by the coating deposition process, the fatigue crack growth under specified loading conditions was simulated in a discrete way to calculate the number of cycles necessary for each crack depth increment to occur. The applied stress intensity factor range $\Delta K_{\text {app }}$ - including the residual stress effect - was calculated by means of nodal displacement extrapolation at the crack tip and microstructural fracture mechanics was applied to evaluate the threshold stress intensity factor range $\Delta K_{\mathrm{th}}$. The hardness distribution in the surface layers of the coated component must also be known to complete the calculation procedure consisting of verifying whether the applied stress intensity factor range is higher than the threshold stress intensity factor range and of determining the crack propagation rate by formula. In $[15,16]$, the procedure was applied to the previously mentioned $\mathrm{CrN}$-coated 2205 duplex stainless steel and H11 tool steel samples tested under four-point bending fatigue. The numbers of cycles until failure calculated were in good accordance with the experimental results showing errors lower than $14 \%$.

Remarkable results were also collected by applying the procedure to transmission spur gears for racing motorcycles [26]. The growth of a semi-elliptical surface crack placed at tooth root was simulated for both steel and titanium uncoated and PVD-coated gears (Fig. 6). The graph of Fig. (7) shows the critical crack depths of the coated and the uncoated gears with the indication of the threshold and the applied stress intensity factors ranges. The relatively low $\Delta K_{\text {app }}$ resulting from both the high residual compressive stresses in the surface layers and the lower substrate elastic modulus made it reasonable to compare the fatigue behaviour of the coated titanium gear with that of the carburized steel one. As a matter of fact, the lower stress intensity factor ranges produced lower crack growth rates in the coated titanium gear than in the coated steel one - say 432,220 vs. 154,160 load cycles to produce a $200 \mu \mathrm{m}$-deep crack.

In [24], the stress distribution underneath and the stress state in the coating of the notched and smooth uncoated and TiN-coated Ti-6Al-4V samples mentioned in the previous section were numerically determined to achieve better understanding of the experimental results. Threedimensional FE models of the samples accounting for the residual stress distribution due to the coating deposition process were generated (Fig. 8a). Furthermore, four different values of coating elastic modulus, say 100, 200, 300 and 400 $\mathrm{GPa}$, were considered in the models to verify the influence of this parameter on the local stress state in the coating and in the bulk material and hence to evaluate the opportunity to adjust its value to improve the performances of the coating in the presence of fatigue loads and notches. Typical values of elastic modulus of TiN can actually fall within the range 


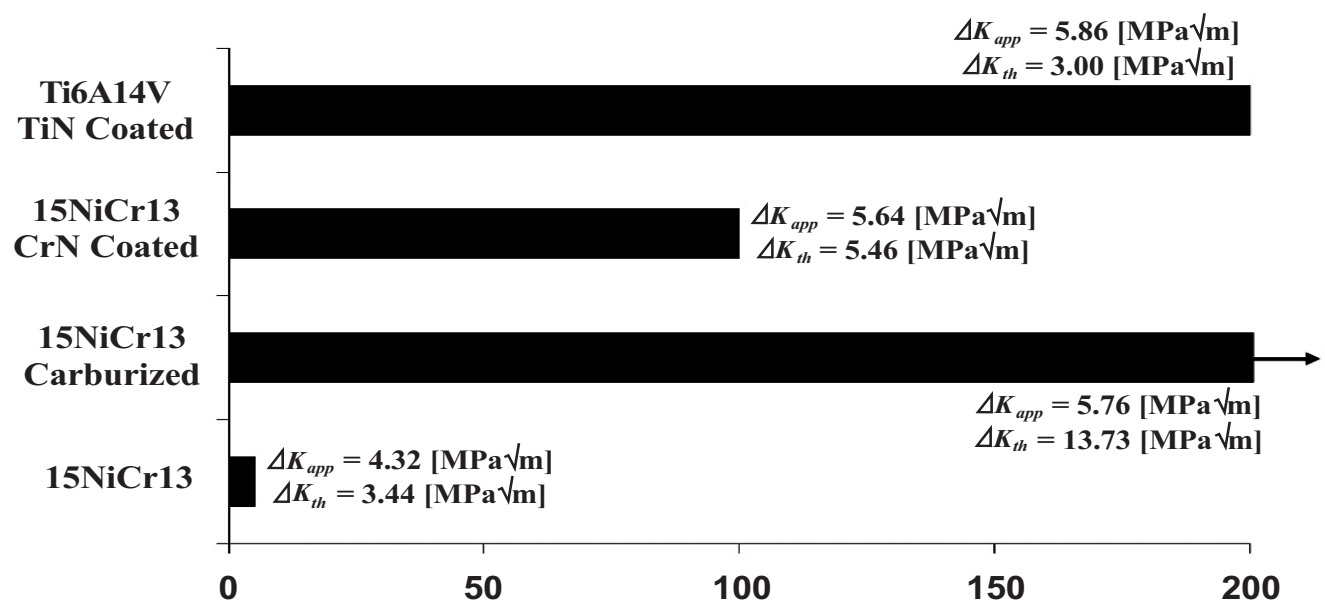

Critical crack depth for crack propagation a $\mathrm{cr}[\mu \mathrm{m}]$

Fig. (7). Critical crack depths of the coated and the uncoated steel and titanium gears studied in [26].

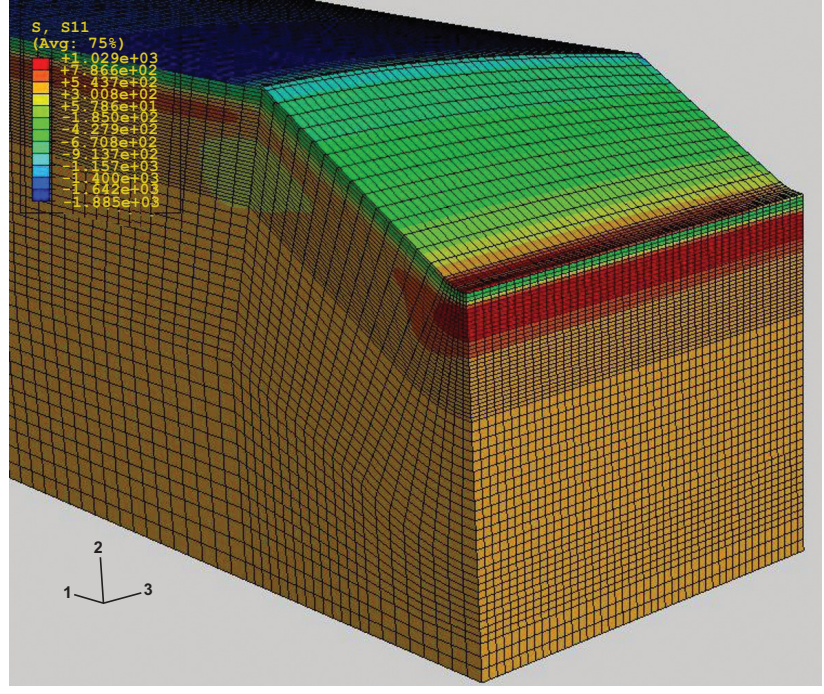

(a)

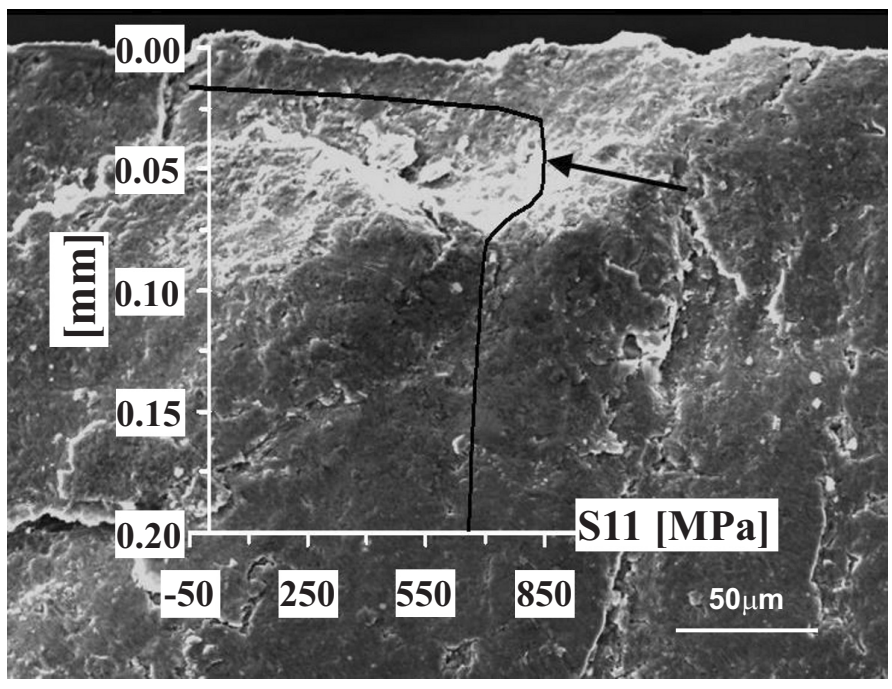

(b)

Fig. (8). (a) Axial stress contour map in the submodel of a notched-coated Ti-6Al-4V sample and (b) superposition of the numerical stress gradient on a micrograph of the crack initiation site in a coated smooth Ti-6Al-4V sample. The arrow points at the maximum tensile stress placed within the nucleation area [24].

300-400 GPa [5,12]. It was pointed out that, regardless of the presence of the notch, the subsurface tensile stresses balancing out the residual stress distribution could have contributed to produce a localized plasticization underneath after the application of the bending load. Fig. $8 \mathbf{b}$ shows the superposition of the numerical stress trend on the fracture surface of a smooth-coated sample. The crack nucleation could actually have occurred where the calculated maximum tensile stresses were present. It was also found that only the local stress state within the coating was affected by the variation of the coating elastic modulus. In fact, similar stress distributions between the smooth- and notched-coated samples were found. This was believed to have contributed to the similar fatigue behaviour observed experimentally. High resultant tensile stresses were achieved in the coating in the two notched samples having the higher coating elastic moduli. By contrast, the less stiff ones kept being under compression after loading regardless of the presence of the notch. As a matter of fact, compressive stresses can keep cracks already present in the coating closed or prevent their formation. In [31], the benefit from having low coating elastic modulus was confirmed by applying Design and Analysis of Computer Experiments (DACE) to finite element models of coated smooth samples for rotating bending tests.

With regard to the reported review of numerical studies, the following points can be underlined:

- In spite of the first good results, the numerical study of the fatigue behaviour of components coated with thin hard corrosion-resistant coatings has not been developed enough yet. In fact, the number of papers dealing with the fatigue life prediction of coated components is very limited. Coated light alloys would deserve particular attention in respect of the opportunity to reduce the mass of mechanical 
components without affecting or even increasing their fatigue strength.

- As a matter of fact, more and more accurate models should be proposed to capture as accurately as possible all the features characterizing the coating and material behaviour and the effects of the deposition process. The experimental validation of the models would be fundamental from this point of view. Furthermore, the experimental research activity could become more effective if planned according to the results of the models.

- The availability of easy-to-apply previsional models would be really important for machine designers, who would account on fast and reliable tools to save working time.

- The integration between structural engineering and corrosion science through proper multiphysics approach to develop previsional procedures to foresee the corrosion-fatigue behaviour of thin hard coated components could constitute a remarkable step forward for many applications.

\section{SUMMARY}

A review of literature findings on the fatigue and the corrosion-fatigue behaviour of components coated with thin hard corrosion resistant coatings is reported in this paper. Good results were often observed, particularly when high surface residual compressive stresses had been produced by the coating deposition process. Only few attempts to simulate and predict the fatigue behaviour in the coating presence by numerical modelling were made. A theoreticalnumerical procedure to calculate the number of cycles necessary to reach specified crack depths in a coated component subjected to prescribed fatigue loads was proposed and validated with good results. The effect of the variation of the coating elastic modulus was also investigated with FE models. Coatings having low stiffness were found to prove effective against fatigue.

In respect of the review presented, the following issues are remarked:

- The fatigue and corrosion-fatigue behaviour of both steel and light alloys when coated with thin hard wearand corrosion-resistant coatings should be investigated further on.

- The range of base materials and coatings should be broadened to achieve the optimization of the performances.

- TiN and $\mathrm{CrN}$ coatings have shown the best outcomes in terms of fatigue resistance because of the high residual compressive stresses generated by the deposition process.

- The current deposition technique is expected to obtain better improvements from coatings deposited at lower temperatures.

- The numerical study of the fatigue behaviour of components coated with thin hard corrosion-resistant coatings has not been developed enough yet.
- The availability of fast and reliable models to foresee the fatigue life of coated components would be really important for machine designers.

- The integration between structural engineering and corrosion science to develop suitable procedures to foresee the corrosion-fatigue behaviour of thin hard coated components should be addressed.

\section{REFERENCES}

[1] Merlo AM. The contribution of surface engineering to the product performance in the automotive industry. Surf Coat Technol 2003; 174-(175): 21-6.

[2] Vetter J, Barbezat G, Crummenauer J, Avissar J. Surface treatment selections for automotive applications. Surf Coat Technol 2005; 200: 1962-8.

[3] Su YL, Yao SH, Wei CS, Kao WH, Wu CT. Comparison of wear, tensile, and fatigue properties of PVD coated materials. Mater Sci Tech 1999; 15: 73-7.

[4] Cunha L, Andritschky M. Residual stress, surface defects and corrosion resistance of CrN hard coatings. Surf Coat Technol 1999; 111: 158-62.

[5] Mendibide C, Steyer P, Fontaine J, Goudeau P. Improvement of the tribological behaviour of PVD nanostratified TiN/CrN coatings An explanation. Surf Coat Technol 2006; 201: 4119-24.

[6] Angelini E, d'Agostino R, Fracassi F, Grassini S, Rosalbino F. Surface analysis of PECVD organosilicon films for corrosion protection of steel substrates. Surf Interface Anal 2002; 34: 155-9.

[7] He JL, Chu $\mathrm{CH}$, Wang HL, Hon $\mathrm{MH}$. Corrosion protection by PECVD-SiO $x$ as a top coating on TiN-coated steel. Surf Coat Technol 1994; 63(1): 15-23.

[8] Moretti G, Guidi F, Canton R, Battagliarin M, Rossetto G. Corrosion protection and mechanical performance of $\mathrm{SiO}_{2}$ films deposited via PECVD on OT59 brass. Anti-Corr Meth Mater 2005; 52(5): 266-75.

[9] Walker M, Meermann F, Schneider J, et al. Investigations of plasma polymerized barrier films on polymeric materials. Surf Coat Technol 2005; 200(1-4): 947-52.

[10] Zajíčková L, Janča J, Peřina V. Characterization of silicon oxide thin films deposited by plasma enhanced chemical vapour deposition from octamethylcyclotetrasiloxane/oxygen feeds. Thin Solid Films 1999; 338(1-2): 49-59.

[11] Guu YH, Hocheng H. Improvement of fatigue life of electrical discharge machined AISI D2 tool steel by TiN coating. Mater Sci Eng 2001; A318: 155-62.

[12] Puchi-Cabrera ES, Matínez F, Herrera I, Berríos JA, Dixit S, Bhat D. On the fatigue behavior of an AISI 316L stainless steel coated with a PVD TiN deposit. Surf Coat Technol 2004; 182: 276-86.

[13] Puchi-Cabrera ES, Staia MH, Ochoa-Perez EA, et al. Fatigue behavior of a $316 \mathrm{~L}$ stainless steel coated with a DLC film deposited by PVD magnetron sputter ion plating. Mater Sci Eng AStruct Mater Prop Microstruct Process 2010; 527(3): 498-508.

[14] Baldissera P, Cavalleri S, Marcassoli P, Tordini F. Study of the Effect of DCT and PVD treatments on the fatigue behaviour of AISI 302 stainless steel. Key Eng Mater 2010; 417-418: 49-52.

[15] Baragetti S, La Vecchia GM, Terranova A. Fatigue behaviour and FEM modelling of thin-coated components. Int J Fat 2003; 25: 1229-38.

[16] Baragetti S, La Vecchia GM, Terranova A. Variables affecting the fatigue resistance of PVD-coated components. Int J Fat 2005; 27(10-12): 1541-50.

[17] Baragetti S, Tordini F. Fatigue resistance of PECVD coated steel alloy. Int J Fat 2007; 29: 1832-8.

[18] Ortiz-Mancilla MJ, Mariño-Berroterán C, Berríos-Ortiz JA, Mesmacque G, Puchi-Cabrera ES. Effect of a thin hard chromium coating on fatigue behaviour of 4140 steel. Surf Eng 2004; 20(5): 345-52.

[19] Kim KR, Suh CM, Murakami RI, Chung CW. Effect of intrinsic properties of ceramic coatings on fatigue behaviour of $\mathrm{Cr}-\mathrm{Mo}-\mathrm{V}$ steels. Surf Coat Technol 2003; 171: 15-23.

[20] Suh CM, Hwang BW, Murakami RI. Behaviours of residual stress and high-temperature fatigue life in ceramic coatings produced by PVD. Mater Sci Eng 2003; A343: 1-7.

[21] Baragetti S, Lusvarghi L, Bolelli G, Tordini F. Fatigue behaviour of 2011-T6 aluminium alloy coated with PVD WC/C, PA-CVD 
DLC and PE-CVD $\mathrm{SiO}_{x}$ coatings. Surf Coat Technol 2009; 203: 3078-87.

[22] Puchi-Cabrera ES, Staia MH, Lesage J, et al. Fatigue behavior of AA7075-T6 aluminum alloy coated with ZrN by PVD. Int J Fat 2008; 30: 1220-30.

[23] Braun R, Schulz U, Leyens C, Hovsepian PE, Ehiasarian AP. Oxidation and fatigue behaviour of $\gamma$-TiAl coated with HIPIMS CrAlYN/CrN nanoscale multilayer coatings and EB-PVD thermal barrier coatings. Int J Mat Res 2010; 101(5): 648-56.

[24] Baragetti S, Tordini F. A Numerical study of the fatigue behaviour of notched PVD-coated Ti-6Al-4V. Struc Durability Health Monit 2007; 3(3): 165-76.

[25] Puchi-Cabrera ES, Villalobos-Gutiérrez C, Irausquín I, La BarberaSosa J, Mesmacque G. Fatigue behavior of a 7075-T6 aluminium alloy coated with an electroless Ni-P deposit. Int J Fat 2006; 28: 1854-66.

[26] Baragetti S. Fatigue resistance of steel and titanium PVD coated spur gears. Int J Fat 2007; 29: 1893-903.
[27] Moinereau D, Brochard J, Guichard D, Bhandari S, Sherry A, France C. Local approach of cleavage fracture applied to a vessel with subclad flaw. A benchmark on computational simulation. ASME Publ PVP 1996; 324: 267-76.

[28] Smith RW. Computer simulation of intergranular stress corrosion cracking via hydrogen embrittlement. Modelling and simulation in materials science and engineering. Mater Sci Eng 2000; 8(4): 62948.

[29] Dejun M, Kewei X, Jiawen H. Numerical simulation for determining the mechanical properties of thin metal films using depth-sensing indentation technique. Thin Solid Films 1998; 323: 183-7.

[30] Souza RM, Mustoe GGW, Moore JJ. Finite-element modeling of the stress and fracture during the indentation of hard elastic films on elastic-plastic aluminum substrates. Thin Solid Films 1999; 355356: 303-10.

[31] Baragetti S, Tordini F. A numerical study on the fatigue and rolling contact fatigue behaviour of PVD-coated steel and titanium spur gears. Eng Comput DOI: 10.1007/s00366-009-0167-9.

(C) Baragetti and Tordini; Licensee Bentham Open.

This is an open access article licensed under the terms of the Creative Commons Attribution Non-Commercial License (http://creativecommons.org/licenses/by-nc/ $3.0 /$ ) which permits unrestricted, non-commercial use, distribution and reproduction in any medium, provided the work is properly cited. 